\title{
QUALITY OF HEALTH CARE SERVICE'S AND PROVIDER'S DETERMINANTS OF HEALTH CARE-SEEKING BEHAVIORS AMONG WOMEN IN KHANA LOCAL GOVERNMENT AREA OF RIVERS STATE, NIGERIA
}

\author{
Nwiko, Kuebari M. ${ }^{1}$, \\ Asogwa, Emmanuel U. ${ }^{2 i}$ \\ ${ }^{1}$ Department of Human Kinetics and Health Education, \\ University of Port Harcourt, \\ Nigeria \\ ${ }^{2} \mathrm{PhD}$, Department of Human Kinetics and Health Education, \\ University of Port Harcourt, \\ Nigeria
}

\begin{abstract}
:
The study examined the quality of health care services and provider's determinants of health care seeking behavior among women in Khana local government area of Rivers State. The study adopted a descriptive cross-sectional survey design. Three research questions and two hypotheses guided the study. The sample size for the study was 1,200 women selected using multi-stage sampling procedures. A validated self-structured instrument, titled, "Determinants of Health Care Seeking Behavior Questionnaire", with a reliability index value of 0.64 was used for data collection. Means and Standard Deviations were used to answer the research questions whole Analysis of Variance was used to test the hypotheses at the 0.05 level of significance. The results of the study showed that the respondents had good health care-seeking behaviors in terms of action on perceived signs and symptoms of disease $(=2.67+0.89)$, test-seeking behavior $(=2.93$ $+0.94)$, choice of health care service's factors $(=3.36+0.76)$, treatment-seeking behaviors $(=2.86+0.95)$, and treatment-adherent behavior $(=2.87+0.85)$. The results also showed that quality of health care service $(=2.90+0.97)$ were significant determinants, while health care provider's factors $(=2.43+1.05)$ were not determinants of health care seekingbehavior of the respondents. The study recommended among others that health care services should be health care consumers-centered to sustain and improve on the health care-seeking behavior and proper re-orientation of health care providers should be carried out at every level of health care in order to create friendly relationship between health care providers and consumers or patients.
\end{abstract}

Keywords: health care service, health care provider, health care behavior

'Correspondence: email asogwaemmanuel2010@gmail.com 


\section{Introduction}

Virtually, all individuals face at least one form of a health problem or another in their lifetime that would require them to seek some form of healthcare or intervention. Health care-seeking behavior is absolutely essential for health promotion, maintenance and restoration, and disease prevention and treatment. Health care means the provision of what is necessary for the health, welfare, maintenance and protection of someone. Park (2007) defines health care as a multitude of services rendered to individuals, families or communities by the agents of health services or professionals for the purpose of promoting, maintaining, monitoring or restoring health. Health care-seeking behavior is any action or inaction undertaken by individuals who perceive they have a health problem or be ill for the purpose of finding an appropriate remedy (Olenya, 2003). People seek health care for a variety of reasons, such as to receive treatment for acute or ongoing chronic medical conditions, for disease prevention and health promotion purposes or simply to satisfy some social or personal needs, such as family planning or employment purposes (Sauver, Warmer, Yawn Jacobson, McGree, Pankratz \& Rocca, 2013).

There are many avenues for seeking and receiving health care. These avenues, according to Nwiko (2021) include self-medication with herbal traditional medicines, self-medication with pharmaceutical drugs, traditional/herbal medical care from practitioners, and modern or orthodox medicines, and watchful waiting with the expectation of self-resolution. Obiechina (2014) classified components of health care seeking-behaviors into five, namely: action on perceived signs and symptoms of disease, test-seeking behavior, choice of health care, treatment-seeking behavior, and treatmentadherent behavior. Action on signs and symptoms is the action undertaken by individuals in response to signs and symptoms of the disease condition. According to Hjeem and Atwine (2011), health care-seeking-behavior is greatly influenced by the manifestation of symptoms of the disease. On the action on perceived signs and symptoms, Obiechina (2014) concurs that health care seeking-behavior depends on an individual's mental understanding of the significance and seriousness of the symptoms.

Kanungo et al. (2015) cited that the nature and perceived severity of illness is an important determinant of health care seeking behavior. In a study, Peppa et al. (2017) found that influenza patients with fever symptoms were less likely to seek medical care, while those with more severe and protracted symptoms were less likely to seek medical care while those with more severe and protracted symptoms were likely to seek care. They noted that individuals with "non-serious" diseases are more likely to ignore the problem altogether, or resort to self-medication at best, while those with severe conditions that interfere with routine activities of life or pose an imminent threat to life are more likely to seek services of health professionals for diagnosis and treatment. Some people may perceive signs and symptoms of the disease as something that need urgent attention, while others may perceive a symptom of disease as something that does not matter as long as one can carry out one's duty actively. 
Test-seeking behavior is conceived by Mirandola et al. (2016) as the active search of individuals to be tested in order to know their health status. Good test-seeking behavior may facilitate rates of disease detection, immediate and appropriate intervention or treatment, and quick recovery and restoration of health. In another land, poor test-seeking behavior or delay may either result from patient's failures to seek health care, or the inability of the health system to detect disease on time. On the choice of health care, studies agree that choice of health care by consumers or patients is, often, influenced by a number of factors, such as genetics, life events, or temperament, pre-disposing factors, such as age, gender, religion, previous health experience from either the patient or someone from the family or friends, knowledge about illness, educational status, availability and accessibility of resources and services (Nnorom, 2019).

Treatment-seeking behavior is the action or nation of an individual to seek a cure of his illness. Morankar and Admassu (2013) state that treatment-seeking behavior of men and women is largely dependent on how he or she and those around them perceive the causes, regarding the diagnosis, accept the treatment, and adhere to the treatment. Treatment-adherent behavior is the extent to which patients or health care consumers take medications as prescribed by trained health care providers. Poor treatment-adherent behavior may cause worsening of disease conditions, and the complications may lead to disability or death if not corrected. Treatment-adherent behavior may depend on some factors, such as age, health status, income, educational status, religion, lack of health information, non-availability and inaccessibility of health services, drugs and facilities.

There are many other factors that could influence or determine people's health care-seeking behaviors which include various socio-cultural, economic and environmental factors. Oberoi et al. (2016) stated that intrapersonal and interpersonal characteristics of individuals, community norms and expectations together with available health provider services are some important determinants of health careseeking behaviors. Scheppers et al. (2006) in their study identified and classified potential barriers levels to the utilization of health care into three levels, namely, patient, provider and system levels. The demographic and structural variables classified under the patient or personal level, include health beliefs and attitudes, personal enabling resources, perceived illness, and personal health practices. Provider level consists of provider characteristics, such as the provider's skills and attitudes. On the system level, Figueroa, et al. (2017) state that the quality of health care, such as accessibility, availability, timelines, convenience and affordability are major determinants of people's desire to seek health care services. According to Nnorom (2019), patients' satisfaction with the quality of service received in a health care facility will encourage or discourage sustained patronage by the patients, and physical factors, such as availability and accessibility of resources and services will facilitate or motivate health care-seeking-behavior change.

Studies identified a number of forms of quality of health care that constitute determinants of health care seeking behavior. These identified determinants include availability, accessibility, costs, distance of travel, protracted waiting time, negative attitude of health workers, cultural beliefs, level of education, and absence of health 
workers at their workplace. Another provision of health care depends on the availability of a regular supply of medication and equipment at the facility level.

Muhammed et al. (2013) cited WHO's report on the reasons for non-utilization of primary health care facilities in most developing countries as being non-availability of essential drugs, high cost of services, inadequate personal, poor community involvement, absence of critical care providers at health care facilities, and negative attitudes of health workers. From study reports, the availability of medicines forms one of the most important elements of the quality of health care and improves health care services. Consequently, low availability of medicines would discourage proper health care seeking-behaviors of people, and encourage self-medication and other inappropriate health care-seeking behaviors. Muhammed and his colleagues further stated from a report by $\mathrm{WHO}$, Africa region that non-availability of essential drugs high cost of services, negative attitude of health workers, absence of medical doctors are the common reasons for non-utilization of primary health care facilities, and also can greatly influence the choice of seeking health care among patients and health care consumers. All these, according to Musoke et al. (2014) may be attributed to poverty.

Accessibility as the quality of health care services is a very good determinant of health care-seeking behavior. Access to health care has four dimensions: availability, geographic accessibility (distance), affordability, and acceptability (Bart, et al. 2012). Accessibility to medicines or health care is a fundamental right of every person. Accessibility to health care is considered the most essential component of any effective health care system. This is because modern pharmaceutical medicine cures, controls and prevents many diseases, and therefore, save many lives and promotes health (Kar, Predhan \& Mohanta, 2010). Regrettably, one-third of the world's population lacks access to essential drugs. In Nigeria for instance, Ushie, Ugal and Ingwil (2016) found that the procedures of obtaining medicines or health care at public health facilities are cumbersome, which often, prompt health care users to seek alternatives in private pharmacies, where service delivery is prompt and client-friendly.

Agency for Health Research and Quality concludes that access to health care strongly influences health care seeking-behavior (Nwiko, 2021). It describes access as gaining entry into the health care system, getting entry into sites of care where patients can receive needed services, and finding providers who meet the needs of patients and with whom patients can develop a relationship based on mutual communication and trust. Actions, behaviors and attitudes exhibited by health workers significantly determine health care-seeking behavior and level of utilization of health care service and patient's patronage to the health care personnel and facilities. Mannava et al. (2015) noted that insensitivity and harshness displayed by most health care providers possess the potential to drive patients away from health care facilities.

Obinna (2018) observed that in Nigeria, the impact of the negative attitude of health workers in both public and private health facilities towards patients is worrisome. He further noted that critical observers are of the opinion that the health institution is losing its focus of genuine concern for the patient and that the managers and other health 
workers are shifting their attention to making financial gains, and as the result, often, consider patients' needs as too demanding. Ibebuike et al. (2017) also concur that negative and unfriendly attitude of health care providers toward health care seekers or consumers significantly affect health care-seeking behavior.

Sule et al. (2008) identified some of the unprofessional and negative attitudes of health workers, towards their patients to include; discrimination of patients and clients based on their status and influence; lack of respect and compassion towards patients; careless and frivolous comments on patients; unreadiness to attends to patent's urgent needs and insensitivity to their plight, laxity dealing with patients waiting for attention; abandonment of place of work for personal gains; and mismanagement of find, drugs and other health care materials. Obinna (2018) also notes that the poor attitude of health workers may have contributed greatly to the unimaginable record of poor performance of the primary health care system in Nigeria.

Revelations of literature show that people seek health care when felt threatened by illness in different forms and sources, and some determinants of health care seeking behavior of patients and health care seekers which include quality of health care services being sought for and the behaviors and attitudes of the health care providers among others. It is based on these observations and reports that the researchers decided to investigate health care-seeking behavior and the impact of quality of health care and providers factors among women in Khana Local Government Area of Rivers State.

\section{Research Questions}

1) What is the health care seeking-behavior among women in Khana Local Government Area of Rivers State?

2) To what extent do quality health care service factors determine health care-seeking behavior among women in Khana L. G. A. of Rivers State?

3) What are the extent health care provider's factors which determine health careseeking behavior among women in Khana L. G. A. of Rivers State?

\subsection{Hypotheses}

1) Quality health care service factors are not significant determinants of health careseeking behavior among women in Khana L. G. A. of Rivers State.

2) Health care provider's factors are not a significant determinant of health careseeking behavior among women in Khana L. G. A. of Rivers State.

\section{Methodology}

A descriptive cross-sectional survey design was adopted for the study. The sample size for the study was 1,200 women selected using multi-stage sampling procedures. The instrument used for data collection was 49 - item self - structured questionnaire titled "Health Care-seeking Behavior Questionnaire (HCSBQ)". The reliability coefficient of the 
instrument was 0.64. The statistical tools used for analysis were Mean and Standard Deviations for research questions and ANOVA for hypotheses at 0.05 alpha level.

\section{Results}

Research Question 1: What is the health care-seeking behavior among women in Khana Local Government Area of Rivers State?

Table1: Health care-seeking behavior among women in Khana Local Government Area $(\mathrm{N}=1,200)$

\begin{tabular}{|c|l|c|c|c|}
\hline S/N & Health care-seeking behavior & $\overline{\boldsymbol{X}}$ & SD & Remark \\
\hline 1 & Actions on perceived signs and symptoms of the disease & 2.67 & .89 & Positive \\
\hline 2 & Test-seeking behavior & 2.93 & .94 & Positive \\
\hline 3 & Choice of health care behavior & 3.36 & .76 & Positive \\
\hline 4 & Treatment-seeking behavior & 2.86 & .95 & Positive \\
\hline 5 & Treatment-adherent behavior & 2.87 & .85 & Positive \\
\hline & Overall grand mean (HCSBQ) & $\mathbf{2 . 9 4}$ & $\mathbf{. 8 8}$ & Positive \\
\hline
\end{tabular}

Data on Table 1 showed that the women displayed good choice of health care behavior $(\bar{x}=3.36+0.76)$, followed by test-seeking behavior $(\bar{x}=2.93+0.44)$, behaviour-adherent behavior $(\bar{x}=2.87+0.85)$, treatment-seeking $(\bar{x}=2.86+0.95)$, and action on perceived signs and symptoms of disease $(\bar{x}=2.67+0.95)$, The table also showed the overall grand mean score of 2.94, which is greater than the criterion mean of 2.50, indicating that women of Khana Local Government Area had good or positive health care-seeking behavior.

Research Question 2: To what extent do quality health care service factors determine health care-seeking behavior among women in Khana L. G. A of Rivers State?

Table 2: Extent to which quality health care service factors determine health care-seeking behavior of women in Khana L. G. A $(N=1200)$

\begin{tabular}{|c|l|c|c|}
\hline SN & Item & $\overline{\boldsymbol{X}}$ & SD \\
\hline 1 & I do not go to the health Centre because it is too far from my house. & 2.56 & 1.07 \\
\hline 2 & The road to the health Centre is too bad. & 2.60 & .99 \\
\hline 3 & I spent so much on transport to get to the health Centre. & 2.80 & .93 \\
\hline 4 & Drug are not always available at the Health Centre. & 3.02 & .92 \\
\hline 5 & I do not always get the prescribed drugs. & 2.88 & .95 \\
\hline 6 & I spend too much money each time I go to the health Centre. & 3.03 & .97 \\
\hline 7 & The primary health care services are not free. & 3.22 & .94 \\
\hline 8 & Health services are not affordable to low-income earner. & 3.12 & 1.04 \\
\hline & Grand mean & $\mathbf{2 . 9 0}$ & $\mathbf{. 9 7}$ \\
\hline
\end{tabular}


Results in Table 2 showed the grand mean score of $2.90 \pm .97$, which is greater than the criterion mean of 2. 50, indicating that quality health care service factors were great determinants of health care-seeking behavior among women in Khana L.G.A.

Research Question 3: What are the extent health care provider's factors which determine health care-seeking behavior?

Table 3: Extent to which health care provider's factors determine health care-seeking behavior of women in Khana L. G. A $(\mathrm{N}=1,200)$

\begin{tabular}{|c|l|c|c|}
\hline S/N & Item & $\overline{\boldsymbol{X}}$ & SD \\
\hline 1 & Always neglected by medical personnel each time I go to health Centre. & 2.49 & 1.16 \\
\hline 2 & The medical personnel are usually rude and unfriendly towards patients. & 2.43 & 1.06 \\
\hline 3 & Health workers make me stay too long whenever I go to health Centre. & 2.16 & .93 \\
\hline 4 & $\begin{array}{l}\text { Health personnel at the health Centre are not efficient in the discharge } \\
\text { of their duties. }\end{array}$ & 2.43 & .96 \\
\hline 5 & There are few trained health personnel at health Centre. & 3.01 & 1.00 \\
\hline 6 & The health personnel do not have empathy for the sick. & 2.49 & 1.14 \\
\hline 7 & The workers are usually partial in the way they attend to patients. & 2.12 & 1.05 \\
\hline 8 & The workers usually shout at patients. & 2.34 & 1.10 \\
\hline 9 & The medical personnel do speak roughly, unfriendly and harshly to patients. & 2.43 & 1.02 \\
\hline & Grand Mean & $\mathbf{2 . 4 3}$ & $\mathbf{1 . 0 5}$ \\
\hline
\end{tabular}

Table 3 showed that mean scores of eight out of nine items were below the criterion mean of 2.50. Furthermore, the grand mean of $2.43 \pm 1.05$ is less than the criterion mean, indicating that health care provider's factors were not determinants of health careseeking behavior of the respondents.

Hypothesis 1: Quality health care services factors are not significant determinants of health care-seeking behavior among women in Khana Local Government Area.

Table 4: Analysis of variance (ANOVA) showing the extent quality health care service factors are not determinants of health care-seeking behavior

\begin{tabular}{|l|c|c|c|c|c|c|}
\hline Source variance & Sum of squares & Df & $\begin{array}{c}\text { Mean sum } \\
\text { of squares }\end{array}$ & F-value & P- value & Decision \\
\hline Between group & 16.990 & 3 & 5.663 & \multirow{2}{*}{14.779} & .002 & Rejected \\
\hline Within group & 309.905 & 1007 & .388 & & & \\
\hline Total & $\mathbf{4 0 7 . 8 9 5}$ & $\mathbf{1 0 1 0}$ & & & & \\
\hline
\end{tabular}

Note: Significant: $\mathrm{P}<0.05$

Table 4 showed $[\mathrm{F}(3,1007)=14.779 \mathrm{P}<0.05]$, indicating that quality health care service factors were significant determinants of health care-seeking behavior of women in Khana L. G. A. Thus, the null hypothesis that quality health care service factors are not significant determinants of health care-seeking behavior of the respondents was rejected. 
Hypothesis 2: Health care provider's factors are not significant determinants of health care-seeking behaviors among women of Khana L.G.A of Rivers State.

Table 5: Analysis of variance showing the extent health care provider's factors are not significant determinants of health care-seeking behavior

\begin{tabular}{|l|c|c|c|c|c|c|}
\hline Source variance & Sum of squares & Df & $\begin{array}{c}\text { Mean sum } \\
\text { of squares }\end{array}$ & F- value & P- value & Decision \\
\hline Between group & 7.391 & 3 & 2.464 & \multirow{2}{*}{3.725} & .111 & Accepted \\
\hline Within group & 666.100 & 1007 & .661 & & & \\
\hline Total & $\mathbf{6 7 3 . 4 9 1}$ & $\mathbf{1 0 1 0}$ & & & & \\
\hline
\end{tabular}

Table 5 showed the sum of squares between groups and within groups are 7.391 and 666.100, while the mean squares for between and within groups are 2.464 and .661, respectively. The degrees of freedom are 3 and 1007 with $\mathrm{F}$ - ratio of 3.725, which is not significant because the probability $(\mathrm{P})$ value of 0.111 is greater than the alpha level of 05 . Therefore, health care provider's factors did not significantly determine health careseeking behavior of women in Khana L. G. A of Rivers State, and the hypothesis was accepted.

\section{Discussion of Findings}

\subsection{Action on Perceived Signs and Symptoms}

The findings in Table 1 revealed that the women of Khana L. G. A demonstrated a good choice of health care behavior. They did not ignore signs and symptoms of disease when they felt sick; they sought health care once signs and symptoms were noticed or manifested. The finding is in line with reports of Herold (2016) which noted that respondent's behavior in relation to signs and symptoms of the disease included resting and waiting, followed by taking over-the-counter (OTC) medication, seeing a health professional and taking a home remedy. In agreement with this study's finding, the study's finding of Mahejabin et al. (2015) found out in their study, 89. 4\% of their respondents sought health care services on notice of signs and symptoms (i.e sickness).

\subsection{Test-seeking Behavior}

Table 1 also showed that the women exhibited good and positive test-seeking behavior. The findings indicated that they went for medical tests on recommendation by medical personnel; went for the medical test without recommendation but on self-motivation; and obeyed instructions for medical tests. The finding is in line with the findings of Ren et al. (2017) who reported that 2,383 men who had casual sex in China engaged in HIV-selftesting, but, however in contrast to Obiechina (2014) findings that the majority of tuberculosis patients in Ibadan, Oyo State, Nigeria did not carry out a test to confirm their TB status. 


\subsection{Choice of Health Care Service}

The study revealed that the respondents displayed good and positive healthcare-seeking behavior in terms of choice of health care services. They chose a treatment Centre that was available in their community; chose a treatment Centre that was nearest to their house; chose a treatment Centre where the best treatment and attention was given, and chose a treatment Centre that was affordable. The finding of the study corroborates the observations of Ibebuike et al. (2017) that utilization of maternal health care is largely dependent on the availability, affordability, accessibility and quality of attention given. Ibebuike and his colleagues reported that 59.7 percent of their respondents responded that they attended antenatal care because of its proximity to their homes.

\subsection{Treatment-seeking Behavior}

The findings of the study showed that the respondents had good and positive treatmentseeking behavior. This finding is consistent with Adam and Aigbokhaode's study (2018), which revealed that 98.8 percent of respondents sought health care when ill, 98.3 percent used medication given. Their preferred places to seek health care when ill among 91.9 percent of the respondents were patient medicine stores. The positive treatment behavior demonstrated by the women of Khana L. G. A of Rivers State may be attributed to high level of awareness and enlightenment programmes on the efficacy of modern health care, the use of health care services and facilities, building and equipping health facilities being embarked upon by Rivers State government and oil exploration companies in the oilproducing communities which Khana is one of them, as the government responsibility and cooperate social responsibilities of the oil exploration companies.

\subsection{Treatment-adherent Behavior}

The study's results revealed that the majority of the respondents demonstrated good and positive treatment-adherent behavior. However, good number of the respondents showed bad or negative treatment-adherent behavior in terms of not being able to keep every clinic appointment due to tight work due, and forgetting to take their medication as prescribed. The finding is not in agreement with the finding of Baudeth (2013) and Dida et al. (2015). Baudeth reported negative treatment adherent behavior among patients receiving antiretroviral therapy in Namibia, attributing it to factors such as spiritual beliefs, stigma, discrimination, non-disclosure of HIV status, and unwillingness to take the medication in the presence of others. Dida et al. (2015) reported 66.2 percent of nonadherence rates among patients with epilepsy in Brazil, due to increased treatment complexities, age and gender. The encouraging good treatment-adherent behavior of women in Khana L. G. A may not be unconnected with improved health awareness and education on the utilization of primary health care services and facilities, and improved literacy level of women in Nigeria. 


\subsection{Quality Health Care Service Factors as Determinants of Health Care-seeking Behavior}

Results in Tables 2 and 4 showed that quality health care service factors were significant determinants of health care-seeking behaviors among women in Khana L. G. A. The findings revealed that distance, location, condition of the road, means and loss of transportation, availability of drugs, and cost of services were found to significantly influence the health care-seeking of the respondents. The majority of the respondents claimed that they did not go to health centres due to far distance from their homes, the road to the centre was bad, they spent too much on transportation to get to the health centre, drugs were not always available at the centre, they spent too much money each time they visited the centres for health care, the services were not free and were not affordable to low-income earners. All these factors constitute accessibility of health care, which Kar et al. (2010) described as the most determinant of health care-seek behavior and utilization of health care. According to Bart et al. (2013), access to health care has four dimensions: availability, geographic accessibility (distance), affordability and acceptability. These findings agreed with Musoke et al. (2014) who observed that utilization of health care services can be influenced by the cost of services, distance to health facilities, cultural beliefs, lack of education, and health facility inadequacies. This study's findings also are in agreement with study findings of Afolabi et al. (2013) which stated that factors that influenced students to seek health care from conventional health facilities include user fees, a distance of travel, dissatisfaction with health care service delivery, unavailability of drugs, and long waiting time.

\subsection{Health Care Provider's Factors as Determinants of Health Care-seeking Behavior}

The results in Tables 3 and 5 showed that health care provider's factors were not significant behavior determinants of health care seeking behavior. These findings implied that the respondents' health care-seeking behaviors were not affected by the actions and attitudes of healthcare providers towards healthcare consumers. This finding is surprising and contrary to popular opinions that negative attitudes towards patients by care providers usually deter them from adopting proper and positive health care-seeking behavior. The finding is not in agreement with many research reports. Mannava et al. (2015) stated that the insensitivity and harshness displayed by most primary health care staff possess the potential to drive patients away from health facilities. Afolabi et al. (2013) also identified unfriendly attitudes of health care workers as a very important determinant of students' non-seeking behavior of medical attention/care at health centres in university communities in Nigeria (Obiechina, 2014). This finding of the study may be attributed to the fact that the majority of the respondents admitted that they sought health care in private clinics, pharmacies, patent-medicine stops and herbal homes where caregivers attended to them properly in order to gain their subsequent patronage. 


\section{Conclusion}

The study concluded that women in Khana Local Government Area of Rivers State had good and positive health care-seeking behavior. And quality health care service factors were determinants of health care-seeking behavior, while health care provider's factors were not.

\subsection{Recommendations}

1) Ministry of health and critical stakeholders in the primary health care delivery system should come up with health programmes and policies that will be health care consumer-centered and friendly. These approaches may help to re-orient health care providers on the need for cooperative and cordial relationships between health care seekers and providers, in order to improve on proper health care-seeking behavior of the public.

2) Government at all non-governmental agencies should address squarely the factor of accessibility of healthcare to the uncovered and under covered populations that need it. This effort should ensure availability, geographic accessibility (distance, proximity), affordability and acceptability of health care at all levels in an efficient and effective manner.

\section{Conflict of Interest Statement}

The authors declare no conflicts of interest.

\section{About the Authors}

Asogwa, Emmanuel U. is a lecturer in Department of Human Kinetics and Health Education, University of Port Harcourt, Nigeria.

\section{References}

Adam, V. Y. Aigbokhaode, A. O. (2018). Socio-demographic factors associated with the health care seeking behavior of heads of households in rural communities in southern Nigeria. Shahel Medical Journal 121; 31 - 36,

Bart, J., Por, Maryam, B., Peter, L. A, \& Wim, V. D. (2012). Addressing access barriers to health services: analytical framework for selecting appropriate interventions in low - income Asian counties. Health Policy and Planning, 27; 288 - 300.

Baudeth, M. F. (2013). Factors association with poor adherence amongst patients receiving antiretroviral therapy at the intermediate hospital Oshakati in Nnambi. A Masters Dissertation, University of the Western Cape

Dida, N., Darega, B., \& Abebe, A. (2015). Treatment-seeking behavior and associated factors among malaria suspected patients in bale zone, south Ethiopia: Institution based cross-sectional study. Journal of Family Medicine 2 (1), 5. 
Figueroa, J. F., Frakt, A. B., Lycon, Z. M., Zhou, X. \& Jha, A.K (2017). Characteristics and spending patterns of high cost among non-elderly Adults in Massachudtts. Health care Amsterdam Netherlands), 5 (4), 165-170

Herold, J. (2016). College students' health seeking behavior plans in response -imagined abdominal pains. A These Submitted to the Graduate School: New Brunswick Rutgers, the State University of New Jersey

Hjeem, K. \& Atwine, F. (2011). Health care-seeking behavior among persons with debate in Uganda: an interview study. BMC International. Health and Human Right.

Ibebuike, J. E., Ojie, C. A., Nwokike, G. I., Obeagu, E. L., Nwosu, D. C., Ezenwuba, C. O., \& Nwagu, S. A. \& Akujuobi, A. U. (2017). Barriers to utilization of material health services in southern senatorial distinct of Cross Rivers State, Nigeria. International Journal of Advanced Multidisciplinary Research, 4 (8); 1-9

Kanungo, S., Bhowmik, K., Mahapatra, T., Mahapatra, S., Hhadra, U. K. \& Sarker, K. (2015). Perceived morbidity, health care-seeking behavior and their determinants in poor - resources setting observation from India https://pubmed.ncbi.nlm.nih.gov/25965382/

Kar, S. S., Predhan, H. S., \& Mohanta, G. P. (2010). Concept of essential medicines and rational using public health. Indian Journal of community Medicine, 35; 10-13.

Mahejabin., F., Parveen, S. \& Begum, R. (2015). Disease pattern and health seeking behavior of slum dwellers in Dhaka City. International Journal of Medical and Health Research, (2); 4-8

Mannava, P., Durrant, K., Fisher, J. \& Luchters, S. (2015). Attitudes and behaviors of internal health care providers in interactions with clients: a systematic review. Global Health, 11;36.

Mirandola, M., Gios, L., Davis, R. T., Furegato, M., Brevegheric, M., Folch, C., Stanekora, D., Nita, T., \& Stehlikora, D., (2016). Socio-demographic factors predicting HIV test-seeking behavior among MSS in GESU cities. European Journal of Public Health, 27(1), 313-318.

Muhammed, K. A., Umeh, K. N., Nasir, S. M., \& Suleman, I. A. (2013). Understanding the barriers to the utilization of primary health care in a low - income setting: Implications for health policy and planning. Journal of Public Health in Africa, 4; 13 $-19$.

Morankar, S., \& Admassu, B. (2013). Determinants of help seeking and treatment-seeking behavior of tuberculosis patients-gender perspective: a systematic review International Journal of Evidence-based on Health Care, 11 (3), 237.

Musoke, D., Boynton, P., Butter, C., \& Musoke, M. B. (2014). Health seeking behavior and challenges in utilizing health care facilities in Wakiso district Uganda. African Health Sciences, 14 (4); 1046-1055.

Nnorom, C. (2019). Predisposing, reinforcing and enabling (PRE) factors: what they are and how to find them. Emel Consulting. 
Nwiko, K. M. (2021). Determinants of health care - seeking behavior among women in Khana Local Government Area of Rivers States M.Sc. Dissertation. School of Graduate Studies, University of Port - Harcourt.

Oberoi, S; Chaudhary, N; Patnaik, S; \& Singh, A. (2016). Understanding health seeking behavior. Journal of Family Medicine and Primary Care, 5 (2), 463.

Obiechina, G. O. (2014). An intervention programme for health care seeking behavior of tuberculosis patients in Ibadan, South-West, Nigeria, A Doctoral Thesis, Graduate School, University of Port Harcourt.

Obinna, C. (2018). How poor attitude of health workers is Killing health care delivery system in Nigeria. Vanguard News. Van guarding. Com.

Olenya, J. M. (2003). Health seeking behavior definition in context, University of Nairobi. East African Medical Journal, 80 (2), 61-62.

Park, K. (2007). Textbook of preventives and social medicine. India: M.S Bansidas Bhanot.

Peppa, M., Edmunds, W. J. \& Funk, S. (2017). Disease severity determines health-seeking behavior amongst individuals with influenza-like illness in an internet-based cohort. Biomedcentral Infection Disease, 17, 238.

Ren, X., WU, Z., Mi, G., McGoogan, J. M., Rou, K; Zhoa, Y; \& Zhang, N. (2017). HIV careseeking behavior after HIV self-testing among men who have sex with men in Beijing, China: a cross-sectional study. Infections Disease of Poverty, 6, 112-118.

Sauver, J. L. S., Warner, D. O., Yawn, B. P; Jacobson, D. J; Mcgree, M. E; Pankratz, J. J., \& Rocca, W. A. (2013). Why Patients visit their doctors: accessing the most prevent conditions in a defined American population: In Mayo Clinic Proceedings, 88(1), 56 -57 , Elsevier.

Scheppers, E; Van -Dongen, E., Dekker, J., Geertz, J., \& Dekker, J. (2006). Potential barriers to the use of health services among ethnic minorities. A Review of Family Practice, 23, 325-348.

Sule, S. S.; Ijadunola, K. T., Onayade, A. A., Fatilsi, A. O., Soetan, R. O. \& Connel, F. A. (2008). Utilization of primary health care facilities: lessons from a rural community in South-West, Nigeria. Nigerian Journal of Medicine, 17 (1), 98 - 106

Ushie, B. A., Ugal, D. B., \& Ingwil, J. A. (2016). Overdependence on for-profit Pharmacies: a descriptive survey of user availability on selected Nigerian States Public Library of Science ONE, 11(11) e0165707. www.mbi.nlm.nch.gov. 
Nwiko, Kuebari M., Asogwa, Emmanuel U.

QUALITY OF HEALTH CARE SERVICE'S AND PROVIDER'S DETERMINANTS OF HEALTH CARE-SEEKING BEHAVIORS AMONG WOMEN IN KHANA LOCAL GOVERNMENT AREA OF RIVERS STATE, NIGERIA

Creative Commons licensing terms

Author(s) will retain the copyright of their published articles agreeing that a Creative Commons Attribution 4.0 International License (CC BY 4.0) terms will be applied to their work. Under the terms of this license, no permission is required from the author(s) or publisher for members of the community to copy, distribute, transmit or adapt the article content, providing a proper, prominent and unambiguous attribution to the authors in a manner that makes clear that the materials are being reused under permission of a Creative Commons License. Views, opinions and conclusions expressed in this research article are views, opinions and conclusions of the author(s). Open Access Publishing Group and European Journal of Education Studies shall not be responsible or answerable for any loss, damage or liability caused in relation to/arising out of conflicts of interest, copyright violations and inappropriate or inaccurate use of any kind content related or integrated into the research work. All the published works are meeting the Open Access Publishing requirements and can be freely accessed, shared, modified, distributed and used in educational, commercial and non-commercial purposes under a Creative Commons Attribution 4.0 International License (CC BY 4.0). 